\title{
Cardiovascular Pharmacotherapy 2010
}

\section{Foreword}

\author{
Jay N. Cohn
}

Published online: 1 September 2010

(C) Springer Science+Business Media, LLC 2010

The International Society of Cardiovascular Pharmacotherapy (ISCP) is dedicated to a world-wide mission to improve management of cardiovascular diseases with knowledgeable application of appropriate drugs. Accomplishing that mission involves providing educational efforts at international meetings.

This special issue of Cardiovascular Drugs and Therapy includes review papers presented at a joint meeting in Beijing of the ISCP and the Great Wall International
Congress of Cardiology held in October 2009. The diverse topics covered in this special issue reflect the broad interest of ISCP and the wide-ranging progress being made in cardiovascular pharmacotherapy.

Drug therapy is a moving target because of both industry's dedication to developing new drugs and academia's continuing commitment to document efficacy. These state-of-the-art papers may ultimately require updating. It is ISCP's goal to keep the medical community abreast of new advances in the field. 